\title{
A response to Professor Mitchell's "simple guide to the nursing process"
}

\author{
ALISON J TIERNEY
}

"Is nursing any business of doctors ?" asks Professor Mitchell. ${ }^{1}$ Of course it is. Whether the business of nursing is best explained to doctors by a doctor, however, seems reasonable to question on the basis of Professor Mitchell's "simple guide to the nursing process." I hope that doctors pay as much attention to the nurse's reply, for Ray Rowden brought balance and perspective into the picture. ${ }^{2}$

It is difficult to be sure of the purpose behind Professor Mitchell's article. Was it a genuine attempt to inform doctors about the nursing process? If so, then a more complete, accurate, and objective account could reasonably have been expected. Or was the main purpose simply to stimulate debate? I am sure that the article will create a lively debate among doctors as it reinforces medical stereotypes of nurses and nursing. Nevertheless, some constructive interprofessional dialogue on the subject is what is needed. Professor Mitchell's approach, in being so deliberately contentious and unreasonably dismissive, is hardly an auspicious beginning.

Many of the criticisms that doctors are directing at the nursing process are really an expression of more general concerns. From the beginning Professor Mitchell conveys his anxiety that the nursing process seems to threaten the doctor-nurse relationship. It is nonsense to believe that nursing and its relation to medicine have not changed over the past 130 years. There has been a continual realignment. The nursing process may contribute to some further change in the doctor-nurse relationship, but we should not obscure discussion about the

\section{Edinburgh EH10 5RH}

ALISO'N J TIERNEY, PHD, RGN, former lecturer, department of nursing studies, University of Edinburgh

Correspondence to: 3 Greenbank Lane, Edinburgh EH10 5RH. nursing process by concentrating on issues of professional territoriality.

Because of preoccupation with these issues doctors are unclear about what the nursing process is. Professor Mitchell explains the origins of the term and, though he names the steps of the process, he does not explain them. If I was asked to describe the nursing process in a nutshell I would ignore all the ideas associated with the term and all the details of its application in practice and instead concentrate on the basic fact that it is a method. The nursing process is a systematic approach to the provision of individualised nursing care. The steps of the process, which logically follow in sequence but may at times overlap, are:

(1) Assessment. On the basis of systematically collected information a patient's nursing needs (commonly expressed as problems) are identified.

(2) Planning. To ensure that the patient's identified nursing needs are met a nursing plan is drawn up. This includes a statement of objectives (sometimes referred to as goals or expected outcomes); an indication of priorities; and specification of the planned nursing intervention.

(3) Implementation. The planned nursing intervention is carried out.

(4) Evaluation. The effectiveness of the nursing intervention is evaluated by comparing actual outcomes with expected outcomes.

Assessment, planning, implementation, and evaluation are steps used in all disciplines (including medicine) and, indeed, in any activity that is approached in a logical, systematic way. To a large extent, nurses have always used the process, though the widespread recognition of the need for evaluation is new. It might have been more useful if I had written a nurse's guide to the nursing process. But I have chosen to respond to Professor Mitchell because he voices the views and concerns of at least a part of the medical establishment. 


\section{Jargon}

Professor Mitchell's comments on jargon illustrate the superficiality of his analysis. Like Ray Rowden, I accept that there is validity in the criticism concerning jargon and the nursing process. Nevertheless, there is a place for new terms if they are genuinely helpful.

The particular example of jargon that is cited is the reference to "next of kin as significant others and meaningful persons." The term "significant others" is not used instead of the term "next of kin" but has been introduced into nursing assessment forms as an addition. ${ }^{3} 4$ The terms are not, as implied, synonymous. Knowledge of a patient's "next of kin" is, as ever, essential. In the context of individually planned nursing care, however, knowledge of the patient's "significant others" is likely to be of greater relevance. Mrs Smith's next of kin might be her estranged husband or, if she is widowed, her son in Australia. Those people who are significant to her-and, therefore, probably also to her recovery and care after discharge-may include her best friend or her sister, her boss or her minister.

It may seem to be nit picking to dwell on such an apparently minor point, but I do this to encourage readers to weigh up Professor Mitchell's expressed doubts about the nursing process with care rather than accept them wholesale.

\section{Nature of nursing}

Doctors seem to think that in the adoption of the nursing process there has been a fundamental change in the way that nurses define nursing, particularly vis à vis medicine. Professor Mitchell seems to imply that there is something new about describing nursing in relation to activities of living (the term I use) and, at least from a medical perspective on patient care, that there is something fundamentally misguided about doing so.

His comments on "the nature of nursing" are difficult to interpet. He states, "The fundamental error is to presuppose that problems of daily living activities can be separated from diagnosis and treatment"; and, "Knowledge of the cause and clinical course of disease must thus precede any plans to remedy the resulting deficiencies of living activities." I do not accept the first statement. A patient's medical condition will be directly responsible for certain problems with the activities of living, but it is not the sole cause of all such problems. I agree with the second statement but only in so far as it pertains to patients with a diagnosed disease.

Whatever the statements say, I believe that they convey the concern that nurses, in focusing on activities of living, seern to have rejected the relevance of medical diagnosis and treatment. This misconception arises because doctors base their view of the nature of nursing on the false idea that all there is to nursing is care of sick people in hospital. The following statements present a broader and more realistic view of nursing and show why the notion of activities of living is more relevant to nursing than the limited concept of disease, which is Professor Mitchell's frame of reference.

- Nurses are extensively concerned with people who do not have a disease-for example, midwives look after pregnant women and health visitors are concerned with mothers and preschool children. The nurse's role here could be described in terms of disease prevention. A broader and more positive view would be to describe it as promoting healthy living, and preventing potential problems with the activities of living from becoming real ones.

Nurses are concerned with the care of babies, young children, the elderly, and people nearing death, who may be patients and may have a disease. But their dependence on nurses for help with the activities of living is primarily because they are young, old, or dying.
- Nurses no longer regard people who are mentally, physically, or visually handicapped as ill. What nurses do for such people, whether in an institution or the community, could be described as helping them to achieve their optimal level of independence in the activities of living.

Nurses who work in the community provide care for many people who, though under medical surveillance, are not receiving medical treatment but do require help (short term or long term) with problems related to activities of living.

- In acute hospital medicine there are patients whose cause of illness is being investigated or is not yet firmly diagnosed, or which eludes clear cut diagnosis altogether. Nevertheless, these patients may need help to continue to perform activities of living and may have specific problems in relation to some of them. A nursing plan is necessary even though knowledge of the cause and course of disease is not available.

In the same context, in almost every hospital ward there are some patients who are no longer receiving medical treatment but who still require nursing care. They remain in hospital because they are not sufficiently independent in the activities of living to be discharged.

- Finally, consider those patients who do have a specific medical diagnosis and who are receiving medical treatment. They may also require help to carry out the activities of living. Problems related to these-for example, difficulties with eating and drinking, eliminating, sleeping, and so on-do not all derive directly from their medical condition. Many problems that patients have (or may develop)-and with which nurses are concerned-have little if anything to do with the disease. They arise simply because the patient is in a hospital ward or is confined to bed, or has part of the body immobilised. There are many other reasons, such as separation from family, enforced absence from work, and the natural fears and anxieties that are evoked by illness and uncertainty.

I have deliberately put the emphasis on those areas and aspects of nursing that are not primarily dependent on medical diagnosis. I have tried to show why the notion of activities of living is, overall, more relevant to nursing than the disease concept that Professor Mitchell adopts in his analysis.

Contrary to his belief, nurses do not consider that a doctor's concern with disease precludes an interest in the person. Likewise, a nurse's focus on a person's activities of living does not preclude consideration of the cause and course of his disease (if he has one). The nursing process has not caused nurses to reject the relevance in nursing of medical diagnosis and treatment. It may have encouraged them to place greater emphasis on health and normality and individuality, but that is not incompatible with the fact that there is a part of nursing solely concerned with medically delegated tasks concerning the treatment of disease. Nurses acknowledge that in some specialties and for particular patients the medical diagnosis and treatment is all important.

There has not been any fundamental change in the way that nurses define nursing. Recent writing on the subject of the nature of nursing is no more than a contemporary version of what Virginia Henderson wrote almost 30 years ago. She identified three distinct areas of activity within nursing: helping the patient to carry out the therapeutic plan as initiated by the physician; cooperating with other members of the health team in planning and carrying out the total programme; and the part of nursing that the nurse initiates and controls. She described the last as follows: "The unique function of the nurse is to assist the individual, sick or well, in the performance of those activities contributing to health or its recovery (or to a peaceful death) that he would perform unaided if he had the necessary strength, will, or knowledge. And to do this in such a way as to help him gain independence as rapidly as possible."'s 


\section{Unnecessarily complex documents}

Documentation in nursing has become more complex as a result of the nursing process. Many nurses are worried about this. Even so, as Ray Rowden pointed out there are many reasons why nursing records need to be fuller and more reliable than previously. His own experience shows that the nursing process need not result in unnecessarily complex documents.

Commenting on the failure of documents to differentiate between the needs of patients with disabling chronic disease and those of patients with life threatening conditions, Professor Mitchell argues for documents that differ from specialty to specialty. His criticisms deserve nurses' attention. If there seems to have been an emphasis on standardisation-for example, in the widespread adoption of an activities of living framework-the reason should be apparent from my comments on the nature of nursing. There cannot be a different process for each specialty, though the documents must take account of the differences and clearly need to reflect more explicitly the relevance of medical information. Nurses would welcome the guidance of doctors in this.

Professor Mitchell illustrates his claim that there is "unnecessary complexity" with material extracted from Using a Model for Nursing. ${ }^{3}$ As one of the editors I can correct some misrepresentation on which the criticisms are based. These are mainly directed at the document designed for the assessment step of the nursing process. The two page patient assessment form could hardly be described as a complex document. One page is for recording biographical and health data and the other for recording information obtained from assessment of activities of living.

Professor Mitchell states that there is "a 12 page checklist" comprising "a prompt list of some 40 to 50 items to be recorded" in respect of each of the 12 activities. This is not the case. What he refers to, and cites for controlling body temperature, is taken from an appendix to the text that contains a collection of chapter summaries from The Elements of Nursing. ${ }^{\circ}$ Taken out of context, it is not surprising that the lists seem bizarre; we presumed that they would not be used other than as an aide mémoire by those who had studied the seminal text. There is some justification for the misrepresentation, but Professor Mitchell might have pondered on an apparent inconsistency between what he interpreted as "a 12 page checklist" and a comment in the final chapter of the book: "We wondered if a checklist for each activity of living might be useful as an adjunct to the patient assessment form. However we consider there are disadvantages in that the nurse may become committed to the narrowness of the specific content of the list, rather than the broad underlying principles." 3 Contrary to the impression provided by Professor Mitchell, we have been at pains to emphasise the need for simple, manageable documents.?

Another point that we have repeatedly made is that nursing assessment must be adapted according to the particular circumstances of each patient and within the limits of available time and staff. For example, in the most recent book we repeat that "in some circumstances not all activities of living need to be considered. ... . Of course, in life threatening emergency situations, only minimal essential data are collected." 3 Had Professor Mitchell adequately studied the text he would not have thought it necessary to remark: "I would sooner see the nurses at the bedside of acute stroke patients, dealing with their real needs and not working their way down a checklist on 'expressing sexuality'."

There is justification for concern that nursing process documents may have become unnecessarily complex and time consuming. But Professor Mitchell's presentation is inaccurate and exaggerated. Comments such as, "The spectacle of a row of nurses beavering away at complex and irrelevant checklists fills me with gloom" will achieve nothing more than an unnecessary increase in the disquiet among doctors.

\section{Theory and practice}

Professor Mitchell attaches too much importance to what has been written about the nursing process and too little to what is happening. What matters-and what is the business of doctors -is what is going on in the name of the nursing process in practice. I know of no firm evidence from doctors to show that the nursing process is adversely affecting patient care.

Nurses are probably spending a bit more time than before on documentation and, so, are spending a bit less time with patients. Is this necessarily to be deplored? In the days of task orientation much time was spent taking temperatures and "doing backs" and the like. Nurses did such things for all patients, irrespective of whether it was really needed or, indeed, had any effect. One objective of individual care plans is to identify things that patients can (and would like) to do for themselves. If there is concern about how much time nurses spend with patients we need to pay as much attention to its quality and purpose as to the amount.

Nursing documents probably are more complex and may seem to contain less medical information than before. In practice, however, has much altered? Nurses may be restoring more emphasis to basic nursing care, but does that necessarily mean that they are neglecting their responsibilities in the area of medically delegated activity? There may be a lot of talk in nursing about autonomy, but in practice have relations between doctors and nurses changed to the disadvantage of patients ?

And what about the effects of the nursing process on patients? Its advocates may cite instances to show that patients positively appreciate the more personalised approach of individually planned nursing. ${ }^{3}$ I have heard of contrary anecdotal evidence, but that seems to be a minority view.

\section{Doctors' attitudes to nurses}

Nurses have much to gain, and little to lose, by discussing the nursing process with doctors. They might be forgiven for wondering if there is any real point in doing so in the current climate. Professor Mitchell's article and others have conveyed a negative and hostile medical response to the nursing process. $^{8}{ }^{9}$ I have read only one constructive medical contribution -written by a general practitioner. ${ }^{10}$

On the subject of poor relations between the medical and nursing professions Professor Annie Altschul has written: "Nurses are now in the habit of thinking deeply about the best way to give the patient good nursing care. They are aware of the complexity of the task of giving high standards of care. They are conscious of the fact that doctors do not know how to nurse, never having been trained to do so, and therefore doctors cannot tell them how to do it."11

Professor Mitchell's attitude is conveyed in his quip, "Never ask a barber if you need a haircut." Perhaps not. But if I wanted information about something new in medicine $I$ would ask a doctor. I think that nurses can reasonably expect doctors to find out from them about the nursing process before dismissing the whole business as misguided, ill conceived, and, by implication, irresponsible.

The former chairman of the BMA's Central Committee for Hospital Medical Services, Mr David Bolt, explained doctors' worries about the process but emphasised that "his impression is that there is rarely conflict at ward level." ${ }^{\circ}$ Doctors and nurses who work closely together in hospitals and in health centres will have taken the trouble to discuss this issue and any areas of conflict. If this has not been happening nurses must accept some blame for the hostility and apparent misunderstanding among doctors.

\section{Quo vadis?}

There is no real question of "no introduction," but I do not wish to give the impression that the nursing process is a fait 
accompli. I agree with Professor Mitchell that the nursing process should not be imposed on those reluctant to adopt it, and I think that most nurses would agree that there is the need to take stock of the position. But the reality is that the nursing process has been widely introduced and even if the term was banned and nursing process documents were withdrawn nurses would continue to adopt its systematic, individualised method.

There is, however, much scope for improvement. We can take a careful look at the language and get rid of real jargon. Nursing process documents should be made as simple as possible and as pertinent to each specialty (or ward) as is necessary. In general, there is room for more flexibility and selectivity in the application of the theory in practice. Nurses have no reason to be complacent: they do have a right, however, to be allowed to explain what they are doing and to defend it.

There is the need for evaluation. It is true that the nursing process has been introduced without prior large scale trials. Nevertheless, its rationale-the need for a systematic, individualised approach-and many specific aspects of each of the steps do have a research base. The nursing process has been the subject of a World Health Organisation programme since 1976: 12 countries in Europe (including the United Kingdom) have been collaborating in this research.12 In Britain there is evidence that, in some areas at least, the introduction of the nursing process is being carefully monitored. ${ }^{13}$ Professor Mitchell suggests evaluation by comparing variables before and after introduction of the nursing process, or on wards that do or do not adopt it. I think that this may be too global because the nursing process subsumes so many different activities and all variables could not be controlled.

I do not think that we should consider evaluating the nursing process in terms applicable to drug trials or other similar, specific innovations. We could, however, study the differences in approach required in acute and long term care; compare the relevance of an activities of living framework with others available; look at the overlap in nursing and medical records and pilot the feasibility of some shared documentation; evaluate particular types of nursing process documents and their relevance in various specialties; investigate possibilities for more self recording by patients; and analyse the data that are being collected in the course of increased documentation-for example, to study the kinds of goals that are being set and if and how these are being attained. The possibilities are endless. But we need first to identify where the problems and uncertainties lie and-not forgetting the interests of those on the receiving end-investigate these with scientific rigour.

Finally, there is a need for discussion among nurses and doctors, but in an atmosphere of mutual trust and with real effort from both sides to aspire to a higher level of debate than has been achieved so far. The nursing process need not become a matter of interprofessional dispute. It could be developed into something that is really useful to nurses, beneficial for patients, and perfectly acceptable to doctors.

\section{References}

${ }^{1}$ Mitchell JRA. Is nursing any business of doctors? A simple guide to the "nursing process." Br Med f 1984;288:216-9.

${ }^{2}$ Rowden R. Doctors can work with the nursing process: a reply to Professor Mitchell. Br Med F 1984;288:219-21.

${ }^{3}$ Roper N, Logan WW, Tierney AJ, eds. Using a model for nursing. Edinburgh: Churchill Livingstone, 1983.

${ }^{4} \mathrm{McF}$ arlane J, Castledine G. A guide to the practice of nursing using the nursing process. London: C V Mosby, 1982.

${ }^{5}$ Henderson V. Basic principles of nursing care. Geneva: International Council of Nurses Publications, 1969:4.

${ }^{6}$ Roper N, Logan WW, Tierney AJ. The elements of nursing. Edinburgh: Churchill Livingstone, 1980.

${ }^{7}$ Roper N, Logan WW, Tierney AJ. Nursing process 5: Endless paperwork? Nursing Mirror 1983; June 22:34-5.

8 Anonymous. Doctors and nurses. Br Med $\mathcal{Y} 1981$;283 :683-4.

9 Bolt D. Why we are worried about the process. Nursing Times 1983; August 24:11-12.

${ }^{10}$ Stanley I. Accountability in nursing 7: Where do we stand with doctors? Nursing Times 1983; September $21: 46-8$.

${ }_{11}$ Altschul A. With all due respect ... Nursing Mirror 1983; July 13:20.

12 World Health Organisation. Medium term programme in nursing/midwifery in Europe, 1976-83. Geneva: World Health Organisation, 1977.

${ }^{13}$ Kemp N. Monitoring the nursing process. Nursing Focus 1983;July/ August:1-2.

(Accepted 21 February 1984)
In some developing countries DDT is still widely used. What hazards arise from this practice, and should any preventive measures be taken?

Dichlorodiphenyl trichloroethane (DDT) has been widely used as a residual insecticide, though its use has declined because of insect resistance and environmental and health concern. DDT is remarkably non-toxic to man in its own right, but with continued exposure it accumulates in the body, especially in fat. It is a potent enzyme inducer, and prolonged exposure may lead to a more rapid destruction of other drugs. ${ }^{1}$ DDT may occasionally cause a contact allergy ${ }^{2}$ but the chief concern has been over its potential carcinogenicity. It is carcinogenic in animals but exposure in man over 20-25 years has shown no evidence of carcinogenesis. ${ }^{3}$ Although this subject is controversial, it seems that the health risks from DDT have been overexaggerated in the past.-M ORME, reader in clinical pharmacology, Liverpool.

${ }^{1}$ Agarwal N, Sanyal S, Khuller GK, Chakravarti RN, Subrahmanyam D. Effect of acute administration of dichlorodiphenyl trichloroethane on certain enzymes to Rhesus monkey. Indian 7 Med Res 1978;68:1001-6.

Pedersen NB, Thormann J, Senning A. Occupational contact allergy to bis-(43 w unster CF, Jukes TH. DDT. $\mathcal{F} A M A$ 1975;231:463-4.

When gem stones are ground on a wheel an aerosol consisting of mineral oil with suspended silicaceous material is produced. Is this a health hazard?

The mechanical processes of cleaning, sawing, grinding, faceting, and polishing precious stones may give rise to highly dispersed aerosols composed of several elements. ${ }^{1}$ These include the stones themselves; the abrasives (probably diamond or cubic boron nitride, second only to diamond in hardness); bonding materials, which hold the abrasive on to the grinding disc; and finally the cutting oils, said in the question to be mineral oils. Neither diamond nor cubic boron nitride are known to damage the lung. ${ }^{2}$ The evidence that inhalation of oil mists might cause cancer of the lung is inconsistent, though the follow up periods have sometimes been short. I know of no recent study of the health effects from grinding precious stones. Nevertheless, because an excess of cancers in the digestive tract had been reported among people manufacturing abrasives, Wang et al from Harvard conducted a mortality study in the optical manufacturing industry. ${ }^{3}$ This included men engaged in manufacturing metal spectacle frames (metal cutting, polishing, and electroplating) as well as those grinding and polishing glass. There was an excess of gastrointestinal cancers and particularly of colorectal cancers. Whether the abrasives, binding materials, or the oil are the cause is not known. The authors, wisely, draw attention to the risk, not only of inhalation but also of ingestion through contaminated food and drink from hands that may be constantly and heavily exposed. The risk of colorectal cancer may be said at present to be suspected not proved. Hygiene precautions to limit both inhalation and ingestion are advisable. - W R LEE, professor of occupational medicine, Manchester.

\footnotetext{
Vol 2. Geneva; International Labour Office, $1981: 1109-10$.

Parkes WR. Occupational lung disorders. 2nd ed. London: Butterworths, 1982:41. Wang J-D, Wegman DH, Smith TJ. Cancer risks in the optical manufacturing industry. Br f Ind Med 1983;40:177-81.
} 